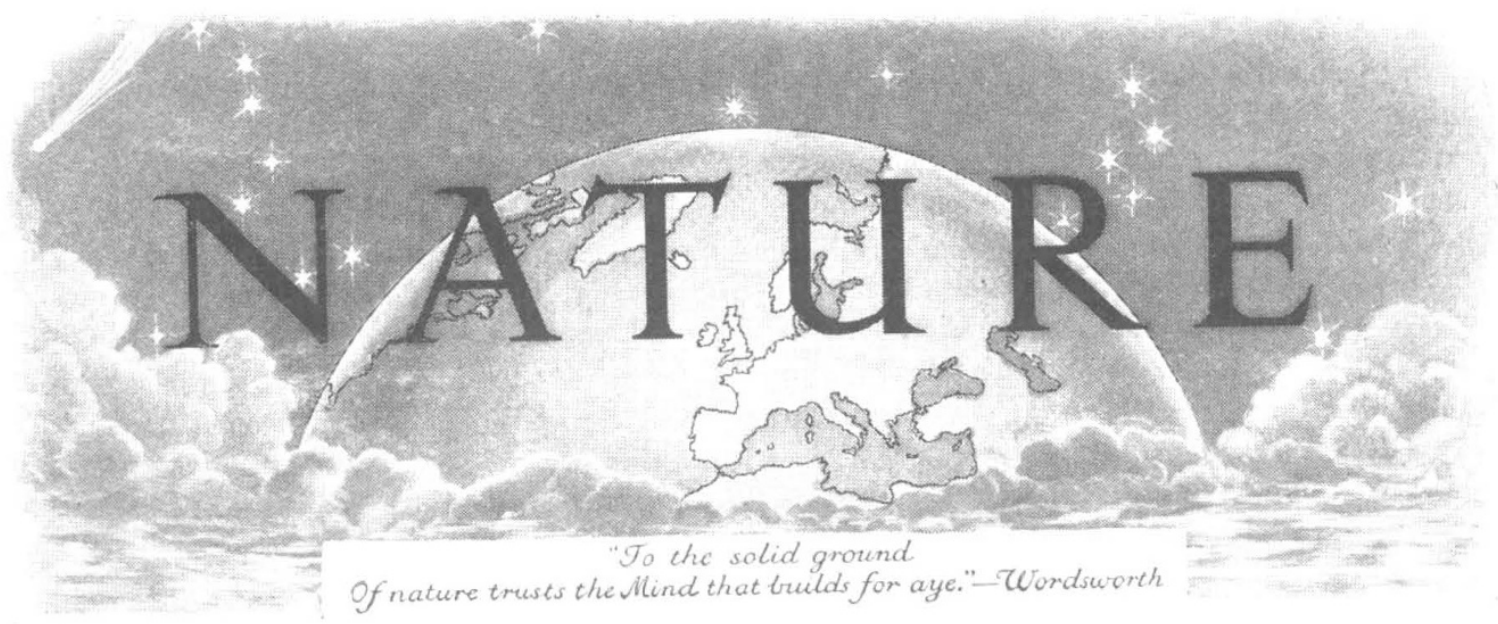

No. 3453

SATURDAY, JANUARY 4, 1936

Vol. 137

\title{
Science and International Policy
}

$\mathrm{I}^{\mathrm{N}}$ a thoughtful study of the international problems poised by the growth of economic nationalism*, F. H. Simonds and Brooks Enemy argue that the price of peace is economic liberty. The implications of this thesis were discussed in the Richard Cobden lecture "The Price of Peace" delivered by H. E. Señor Don Salvador de Madariaga in May of last year (London : R. CobdenSanderson, Ltd., 1935). This lecture merits some attention from scientific workers by reason of the scientific and impartial manner in which it examines the question of peace. More detailed attention was directed to the matter in a conference recently held in London under the auspices of the National Peace Council on "Peace and the Colonial Problem".

In these discussions, the scientific worker will find much material to assist him to find his way to a reasoned opinion on the matter which may have some claims to be considered unbiased. The need for a scientific study of such matters is unfortunately only too apparent in recent actions or discussions bearing on peace. To take only two examples, the publications thus far issued by the Air Raid Precautions Department indicate little appreciation of the way in which air-conditioning might

* The Price of Peace: the Challenge of Economic Nationalism. By F. H. Simonds and Brooks Enemy. (London: H. Hamilton, Ltd. 1935.) be used as a safeguard in the event of gas attack, and there has been little evidence that authority appreciates the way in which an extension of airconditioning methods might form not only an additional safeguard in the event of emergency, but also an immediate contribution in the sphere of industrial or public health.

Similarly in the discussions on sanctions, little regard has been paid to the suggestions outlined by Sir Thomas Holland in his presidential address at the South African meeting of the British Association in 1929, on "International Relationships of Minerals", and more recently in "The Mineral Sanction as an Aid to International Security", regarding the significance of minerals for munition purposes and the effect of treating minerals as munitions or arms in cases of aggression. The value of a considered scientific exploration of these possibilities at the present time cannot easily be overemphasised, and, were it available, the application of sanctions to arrest the present conflict might well be made much more rapid and effective.

That there is need of much scientific thought in these matters before we can hope even to outline a policy which holds out some real promise of eliminating the causes of international friction and promoting international co-operation in the development and use of world resources for the 
world community as a whole, and not in the interests of merely a section or sections, however powerful, can scarcely be gainsaid. This, however, is only the starting point. Even when we are able to outline such a policy, there remains the difficult task of securing its adoption by public opinion in those countries where free expression of opinion is still possible, and of teaching dictatorship elsewhere that it is highly dangerous to themselves to hinder the development of that policy.

The difficulty of this task is apparent when we recall that a radical change in the outlook of nations is required. The true cause of war is the prevalence of the national point of view, and the difficulties which have beset the putting into operation of economic sanctions against Italy illustrate the way in which sectional and national points of view continually threaten and hinder co-operate action, even against the most undisguised acts of aggression.

The discarding of such national selfishness is an essential part of the price which has to be paid for peace, and the whole course of events in the recent months strangely underlies the points made by Señor de Madariaga so long ago as last May. We have seen the nations reluctantly admitting the necessity of sacrificing the free shaping of the aims of foreign policy, struggle though some of them still do to retain their wonted freedom. The Abyssinian dispute has emphasised too the necessity of treating international affairs, before they have become conflicts, by a small group of experienced men, assisted by an organised staff of experts. These things are essential if the policy of mutual assistance, so tardily shaping itself for Abyssinia, is to become part and parcel of living international politics.

It is in fact only when the pooling of policy is accepted that the armament question can be treated on rational lines, because national sovereignty over armaments has been sacrificed. Until this stage has been reached, no matter how sincerely and genuinely a country may protest that its armaments need expanding in order to meet its possible obligations on behalf of the League, any steps so taken to increase its armed forces are just as likely to promote suicidal competition as the most blatant expansion of a militarist nation. Between a national armament policy and the adjustment of armaments on an international basis by an international authority there is no alternative, and only the latter policy in the long run can ensure peace.
When we consider how much is involved in this policy-the surrender of the national right to use armaments as we please and the acceptance of obligations only to use them for the aims of commonly agreed policy, the abandonment of our right to decide alone what should be our armed strength, and the disclosure to the world of the secrets of our armed forces-we begin to appreciate the immensity of the task of educating public opinion for these changes, and the insistence with which Señor de Madariaga pleaded that of all the requirements of peace none was more urgent and more imperative than the organisation of means of objective and impartial information. Co-operation in the organisation and use of a genuine international news agency is one of the first and most fundamental tasks in the organisation of peace.

One of the most difficult problems of civilisation is in fact how to eliminate the war spirit fostered by commercial competition without depriving the world of the zest and stimulus of private initiative. The fear of monopoly, of the withholding of essential colonial raw materials, is already causing alarm, and the desire for a guarantee that the distribution of raw materials will not be unfairly impeded is stimulating the demand for further inquiry. It is because the mandatory system provides expression for the point of view of the world community that demands for strengthening and generalising this system are growing. Once we admit the existence of a world community, the unfettered domination of any race or tribe by any one nation can no longer be justified, and the least that must be granted to the requirements of peace is that all colonial possessions should be held as trusts on behalf of the world community. This alone would calm down unsatisfied colonial ambitions, and, by opening the doors to international trade, would do much to ease the tension between the world powers.

At the conference on peace and the colonial problem, Sir Arthur Salter advocated the extension of the mandatory principle in this way to British non-self-governing colonies, and was supported by Mr. Norman Bentinck, who pointed out that such a development would involve abandoning the system of imperial preference in such colonies, which by closing or reducing the market in these colonies to foreign countries was one cause of the present trouble. Once again we are brought to realise the immense complexities of the problem of peace and of international 
relations, and the impossibility of isolating factors or problems in exactly the same way as in the physical sciences. Prof. Julian Huxley's plea for the development of an appropriate technique, which is capable of dealing with multiple causation and multiple effect as an essential step in the evolution of a true social science, could scarcely be more emphatically endorsed. The study of peace, the scientific determination of the price which has to be paid and the organisation which has to be developed or created to ensure peace, is one in which the scientific worker as such, and not only as a citizen, is called to play a part. Nowhere is it more essential than here that seience should become a real brain for society and not a series of isolated nerve centres, and the first step to that end is taken only when the scientific citizen gives his own mind to this great and urgent problem.

\section{$\mathrm{N}$ at u ra 1 Gas}

\section{Geology of Natural Gas}

Edited by Henry A. Ley. Pp. xii + 1227. (Tulsa, Okla. : American Association of Petroleum Technologists ; London: Thomas Murby and Co., 1935.) 6 dollars; $26 s$.

$\mathrm{T}$

HE efforts of forty-seven authors working to an accepted plan have produced a most comprehensive geological account of the occurrence of natural gas on the North American Continent. The subject is one of increasing interest as more and more use is being made of natural gas both by industrial and domestic consumers. The potentialities for the future are immense, as is evidenced by the fact that the present combined daily open flow capacity of commercial gas wells in the important proved and producing areas exceeds 55 billion cubic feet per day, of which less than 10 per cent was consumed in 1933: there is still great waste of gas. The reservoirs for the future are thought to be infinitely greater, and there is said to be no known geological reason why the present levels of production cannot be maintained for many years.

Gas has as great a range as petroleum in the geological age of the rocks in which it is found, but an unsolved problem is the presence of gas only without associated oil in extensive areas : the same is true of other parts of the world. One suggestion is that gas migrates ahead of oil ; others relate its presence to the critical permeability value of the rocks.

The papers on the various gas-yielding areas in the volume under notice are arranged in a north to south sequence beginning with Alberta and Ontario in Canada and ending with West Virginia and the Mexican oilfields. These are full of geological and production details with sections and maps, and scarcely lend themselves to comment, though it is soon apparent under what diversity of conditions gas is found and how its composition varies. In Alberta, for example, there is an increase in the proportion of higher hydrocarbons to methane.

Some of the fields yield gas rich in helium and nitrogen, the percentage of helium in the richest gases ranging between 1.0 and 8.0 per cent. A gas rich in helium has been found in Ontario, but in small supply and at a low pressure. Elsewhere in the world natural gases are poor in helium. There is some evidence that it is derived from the radioactive elements in the crystalline basement rocks.

In the western part of the United States the gas is rich in carbon dioxide, whereas in the 'sour gas' from western Texas hydrogen sulphide is a constituent and must be removed before the gas can be put to domestic uses.

It is of interest that the wide use of natural gas began about 1891 when compressors were first designed for its transmission by pipe-line : such gas contains about 72.5 per cent of methane and 15.4 per cent of ethane.

The problem of wasted gas is receiving more attention, though probably not more than half of that lost could be economically conserved. The surplus is sometimes stored underground in depleted gas reservoir rocks. In the Zoar field near Buffalo, as much as two hundred million cubic feet are seasonally stored each year in this way without loss.

As is well known, the higher hydrocarbons are separated from the methane and ethane before these latter are transmitted by pipe-line often as much as 1,000 miles to replace retort gas made from coal. The propane is being sold compressed to a liquid in steel bottles in yearly increasing quantities for household purposes in places where there is no town's gas available. The butane is used for industrial heating and for enriching petrol which is deficient in the low-boiling fractions. By pyrolysis it can be converted into higher 